\title{
The Relationship between Human Rights and Disaster Risk Reduction Revisited: Bringing the Legal Perspective into the Discussion
}

\author{
Karen da Costa
}

Ph.D. in International Law, Graduate Institute of International and Development Studies, University of Geneva; Research Associate in International Law, Faculty of Laws, University College London k.costa@ucl.ac.uk

\section{Paulina Pospieszna}

Ph.D. in Political Science, University of Alabama; Assistant Professor of Political Science, Adam Mickiewicz University of Poznan, Poland paulina.pospieszna@amu.edu.pl

\begin{abstract}
This paper explores the link between human rights and disaster risk reduction. We revisit the notion of a human rights-based approach in the context of natural disasters, analyzing how this concept may contribute to greater accountability and empowerment of those involved in disaster risk reduction. To better understand the processes of empowering rights holders and holding duty bearers into account we adopt legal analytical lenses. By doing so we review four country case studies and their main regulations on disaster risk reduction, taking into account the extent to which they adopt a human rights-based approach. We argue that countries whose legal frameworks allow for community engagement point towards greater community empowerment. Similarly, countries whose legal provisions make possible for holding States accountable for their underperformance in disaster situations suggest greater levels of accountability. We also consider key international human rights instruments binding the four
\end{abstract}

* The authors would like to thank for the support of cost Action Disaster Bioethics IS 1201. The paper would not be possible without the short-term scientific mission (STSM) granted to the authors. The earlier versions of this paper were presented in 2014 at the workshops organized within cost Action Disaster Bioethics at the University of Copenhagen and University of Malta. 
case studies in order to analyze whether and to what extent international human rights obligations may support advocacy and accountability in disaster risk reduction. Based on the analysis of these case studies we consider that empowerment and accountability processes in DRR can reinforce each other, and that human rights may contribute to progress in these areas.

\section{Keywords}

natural disaster - human rights - disaster risk reduction - disaster prevention - human rights-based approach - vulnerability

\section{Introduction}

In 2005, the Hyogo Framework for Action (HFA) ${ }^{1}$ was adopted during a UN conference gathering many representatives of international governmental organizations (IGOs), non-governmental organizations (NGOs), national governments, academia, and the private sector. This document contains commitments and priorities aiming at reducing disaster risks, including through "policy, legislative and institutional frameworks". Specifically, it includes the following priority actions and strategic activities for States: 1) to ensure that disaster risk reduction is a national and local priority with a strong institutional basis for implementation; 2) to identify, assess, and monitor disaster risks and strengthen early warning systems; 3 ) to develop better knowledge management for building a culture of safety and resilience; 4) to reduce the underlying risk factors; and 5) to enhance preparedness for effective response. $^{2}$

Since its adoption, the HFA has ignited the passage of a significant amount of legislation ${ }^{3}$ in many countries that is aimed at increasing the attention to

1 'Hyogo Framework for Action 2005-2015: Building the Resilience of Nations and Communities to Disasters (Extract from the Final Report of the World Conference on Disaster Reduction)', World Conference on Disaster Reduction, 18-22 January 2005, http://www.unisdr.org/2005/ wcdr/intergover/official-doc/L-docs/Hyogo-framework-for-action-english.pdf (last accessed 20 November 2014).

2 Hyogo Framework, supra note 1, at 1.

3 'Interim National progress report on the implementation of the Hyogo Framework for Action 2011-2013, October 2012, at 8, http://www.preventionweb.net/files/28830_eth_NationalHFA progress_2011-13.pdf (last accessed 20 November 2014). 
disaster risk reduction (DRR). ${ }^{4}$ However, there are considerable differences in the legal framework for disaster management between disaster-prone countries. This contributes towards making some societies more vulnerable to disasters than others. ${ }^{5}$ It is argued that vulnerability of individuals to disasters may be reduced if laws and policies incorporate a human rights-based approach (HRBA).

In our paper we revise the human rights-based approach to disaster risk reduction by focusing on accountability and empowerment processes. We review the legislation on disasters, especially legislation pertaining to DRR, in order to understand whether it facilitates the empowerment process of local communities by enabling them to claim their rights and thus to hold governments into account when disasters take place. We take a closer look at four country case studies, each representing one different category in relation to their national legal framework on disasters, as identified by a study conducted by the International Federation of Red Cross and Red Crescent Societies (IFRC). ${ }^{6}$ They are: Ethiopia (no specific law on natural disasters), Nepal (response focus), Brazil (disaster management focus), and Dominican Republic (disaster risk management including a DRR focus). The paper contributes to a better understanding of the notions of disaster risk reduction and human rights, and how the two concepts relate to each other. It also provides an account of the extent to which national legislation was adopted in the four case studies following the $2005 \mathrm{HFA}$.

4 According to the United Nations International Strategy for Disaster Reduction (UNISDR), the notion of DRR relates to "the concept and practice of reducing disaster risks through systematic efforts to analyze and manage the causal factors of disasters, including through reduced exposure to hazards, lessened vulnerability of people and property, wise management of land and the environment, and improved preparedness for adverse events." See UNISDR, 'Terminology on Disaster Risk Reduction', 2009.

5 B. Wisner et al., At Risk: natural hazards, people's vulnerability and disasters (2003); B. Wisner, 'Vulnerability', in R. Kitchin (ed.), International encyclopedia of human geography 176 (2009).

6 International Federation of Red Cross and Red Crescent Societies, 'Better Laws, Safer Communities? Emerging Themes on How Legislation Can Support Disaster Risk Reduction', May 2013, http://www.ifrc.org/en/what-we-do/idrl/about-disaster-law/legislation-for -disaster-risk-reduction/ (last accessed 27 November 2014). A later IFRC report adopts a slightly different typology of DRM Laws, taking into account how much priority is given to DRR in DRM laws' objectives and mandates. The classification uses four categories: (1) No DRM Law; (2) Low priority; (3) Medium priority, and; (4) High priority. See International Federation of Red Cross and Red Crescent Societies (IFRC) and United Nations Development Programme (UNDP), 'Effective Law and Regulation for Disaster Risk Reduction: A MultiCountry Report', 2014, at 12 and 42. 
We further identify that differences between successful implementation of disaster laws are often linked to the fact that in some countries communities were well enough informed, engaged, and resourced to take an active part in reducing risks, which did not happen in other cases. Thus, in our view the analysis of communities' empowerment process provides insightful observations in the assessment of countries' disaster preparedness. With this in mind, we review available legal mechanisms at the national level for victims of disasters to seek justice, in order to understand how far accountability is a way open for potential victims. Since we find these mechanisms to be largely insufficient or inadequate, we also look at the international system to observe whether international human rights monitoring mechanisms in particular can hold States accountable for their underperformance in disaster situations. From this analysis we conclude that a human rights-based approach to disaster risk reduction may reduce community vulnerability, thus enhancing resilience. ${ }^{7}$

The paper consists of four parts. First, we present the theoretical framework of the human rights-based approach, together with a review of the literature concerning disaster risk reduction. Second, we analyze our case studies' legal framework for disasters, especially on disaster prevention, in order to assess whether they support community empowerment and State accountability. Then, we take a closer look at the international legal framework binding the four case studies, identifying the obligations for States in relation to prevention of disasters, and whether victims may claim violation of these provisions. Finally, we present findings and conclusions. \\ Theoretical Framework: Human Rights-Based Approach}

Human rights are rights inherent to all human beings. All human beings, regardless of nationality, place of residence, sex, national or ethnic origin, color, religion, language, or any other status are endowed with dignity, which is protected through the idea of human rights. As proclaimed by the UN General Assembly in the Universal Declaration of Human Rights adopted on 10 December 1948, this is a common standard of achievement for all peoples and all nations. Human rights consist of civil and political rights, such as the right to life, equality

7 On resilience in disaster situations see J.C. Gaillard, 'Resilience of traditional societies in facing natural hazards', 16 Disaster Prevention and Management 522 (2007); S.B. Manyena, 'The concept of resilience revisited', 30 Disasters 433 (2006); and J. Twigg, 'Characteristics of a Disaster-Resilient Community', Aon Benfield UCL Hazard Research Centre, 2 November 2009. 
before the law, and freedom of expression; economic, social and cultural rights, such as the rights to work, social security, and education; and collective rights, such as the right to development and self-determination of peoples. ${ }^{8}$

Given the above, rights-based approaches support mechanisms that ensure that rights of human beings are realized and safeguarded (see Figure 1). Human beings as right-holders can claim their rights and demand from duty-bearers for their fulfillment. The State as the main duty-bearer, by adopting international human rights law, has both the moral and legal obligation to respect, protect, facilitate, and fulfill human rights. ${ }^{9}$ The State has the obligation to prevent loss of lives, including losses of economic and social assets, and to prevent other human rights violations, whether caused by human or natural forces.

The advantage of using the language of "right-holders" and "duty bearers" is that it brings clarity to the finding of who is entitled to what vis-à-vis whom. ${ }^{10}$ Therefore, the human rights-based approach leads to greater accountability and empowerment of those involved in the disaster management process. A State should be accountable for its actions, and there should be an effective mechanism that includes specific measures to ensure that States' obligations are carried out. At the same time people should be empowered to claim their rights. This suggests that people should have knowledge and information regarding their human rights; that they should be able to individually or collectively take actions to fully realize their potential; and that they should also be able to communicate effectively, both among themselves, and with duty-bearers. ${ }^{11}$

Although initially conceived to be used in the framework of development, the human rights-based approach is increasingly also referred to in the context of natural disasters. ${ }^{12}$ From a human rights perspective, States, as

See UN Office of the High Commissioner for Human Rights website, http://www.ohchr .org/en/issues/Pages/WhatareHumanRights.aspx (last accessed 27 November 2014).

U. Jonsson, 'Human Rights Approach to Development Programming', Unicef United Nations Children's Fund, Eastern and Southern Africa Regional Office, April 2003.

10 W. Kälin, 'A Human Rights-Based Approach to Building Resilience to Natural Disasters', Nansen Conference on Climate Change and Displacement in the 21st Century, 6 June 2011.

11 Jonsson, supra note 9, at 18.

12 Kälin, supra note 10. For an account on the practical use of adopting a human rightsbased approach in relation to natural disasters, with illustration on post-disaster response in Haiti, see B. Jr. Concannon and B. Lindstrom, 'Cheaper, Better, Longer-Lasting: A RightsBased Approach to Disaster Response in Haiti', 25 Emory International Law Review 1145 (2011). For an analysis of key international human rights law aspects and their potential relevance to reducing the negative impact of hazards see D. Fisher, 'Legal Implementation of Human Rights Obligations to Prevent Displacement Due to Natural Disasters', 41 Studies in Transnational Legal Policy 551 (2010). 


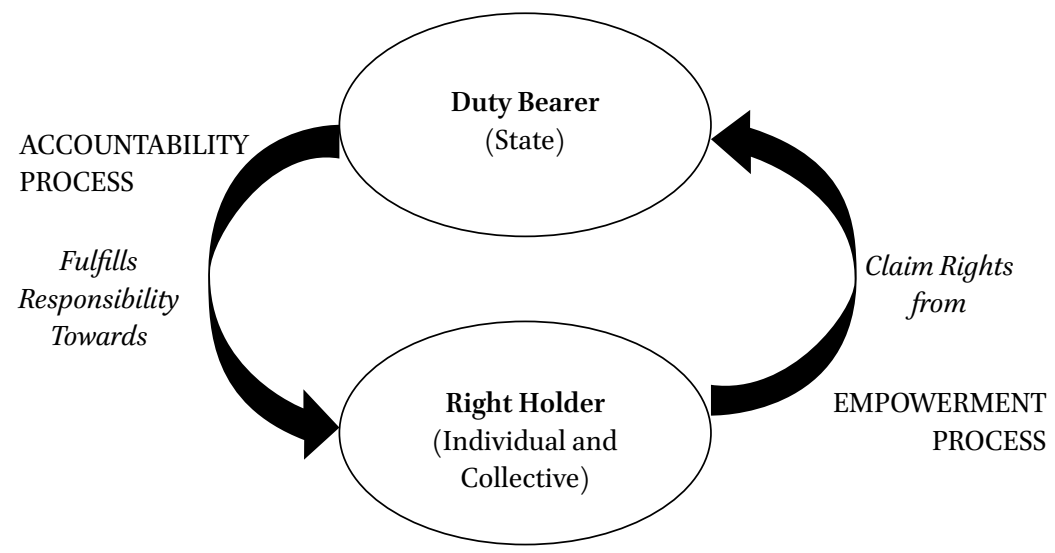

FIGURE 1 The Human Rights-Based Approach: Relationship between Accountability and Empowerment processes. SOURCE: BASED ON THE RECIPROCAL RELATIONSHIP BETWEEN RIGHTS HOLDERS AND DUTY BEARERS IN HUMAN RIGHTS-BASED APPROACH DEVELOPED BY THE UN AGENCIES, SEE FOR EXAMPLE UNFPA WEBSITE AT HTTP://WWW.UNFPA.ORG/RIGHTS/APPROACHES.HTM (LAST ACCESSED 27 NOVEMBER 2014).

the main duty-bearers, have the primary duty and responsibility to provide assistance to persons affected by natural disasters and to protect their human rights. ${ }^{13}$ After a natural disaster strikes a country, States have the duty to provide at least the bare minimum of food, water, clothing, shelter, and health services necessary for the survival of the affected population. If these minimum core obligations, secured, for example, under the International Covenant on Economic, Social and Cultural Rights, ${ }^{14}$ are not fulfilled, a State party to this treaty may be found in violation of some of its human rights obligations contained therein. States may also violate human rights by not engaging in disaster risk reduction, which, if undertaken, could have prevented the occurrence of a disaster. ${ }^{15}$

13 Brookings-Bern Project on Internal Displacement, 'Human Rights and Natural Disasters. Operational Guidelines and Field Manual on Human Rights Protection in Situations of Natural Disaster,' March 2008, http://www.refworld.org/docid/49a2b8f72.html (last accessed o3 December 2014).

141966 International Covenant on Economic, Social and Cultural Rights, 993 UNTS 3 (ICESCR).

15 F. Rawinji, 'Claiming the Human Right to Protection from Disasters: The Case for Human Rights-based Disaster Risk Reduction', http://www.preventionweb.net/files/ submissions/31225_righttodisasterprotection.pdf (last accessed 26 November 2014). 
If accountability mechanisms are in place, they are likely to increase instances in which States can be held responsible. For example, right-holders may use such mechanisms when they consider States have failed to discharge their legal obligations. Through the use of available accountability mechanisms, a process of right-holders' empowerment takes place. In a nutshell, accountability and empowerment reinforce each other.

We argue that a good way to better understand whether and how the human rights-based approach can be used in disaster situations is through adopting legal analytical lenses. Law is certainly not a panacea, ${ }^{16}$ but, taking into account that empowerment and accountability processes are closely anchored in legal frameworks, it is suggested that law does play an important role in reducing the risk of disaster. The process of empowerment through the law suggests strengthening the capacity of everyone to exercise their rights, either as individuals or as members of a community. ${ }^{17}$ The human empowerment framework developed by Inglehart and Welzel shows that the empowerment of people, although it is facilitated by people's objective capabilities and subjective motivations, cannot take place without "their legal entitlements to pursue self-chosen activities and mutually agreed interests with others." ${ }^{18}$ In a similar manner, for accountability to be achieved, there is a need for legal rules to be in place, so that claims can be made for holding those liable into account. ${ }^{19}$

16 Paraphrasing Wisner et al., 'Political Will for Disaster Reduction: What Incentives Build It, And Why Is It So Hard To Achieve?' (2011), Draft 7 B.

17 On the importance of community empowerment and involvement in disaster risk reduction see for example C. Benson, J. Twigg and M. Myers (2001), 'NGO Initiatives in Disaster Risk Reduction: an Overview', 25(3) Disasters 199 (2001); J.C. Gaillard and J. Mercer, 'From knowledge to action: Bridging gaps in disaster risk reduction', 37 Progress in Human Geography 93 (2012); R. Shaw, A. Sharma, and Y. Takeuchi (eds.), Indigenous Knowledge and Disaster Risk Reduction: From Practice to Policy (2009); R. Shaw, N. Uy, and J. Baumwoll (eds.), Indigenous Knowledge for Disaster Risk Reduction: Good Practices and Lessons Learnt from the Asia-Pacific Region (2008).

18 R. Inglehart and C. Welzel, Modernization, Cultural Change and Democracy: The Human Development Sequence (2005), at $15^{2}$.

19 Similar rationale seems to be reflected in the UN International Law Commission articles on the protection of persons in the event of disasters. Article 6 indicates that persons affected by disasters are entitled to respect for their human rights, though there is no indication on what this provision entails. The ILC articles may give rise to an international treaty on the subject. They have been transmitted to, among others, governments, and comments are expected to reach the ILC by 1 January 2016. 


\section{Addressing Vulnerability through Empowerment and} Accountability in National Disaster Legislation

The literature gives enough reasons why human rights relate to natural disasters, and why applying a human rights-based approach to disaster risk reduction is important. Although international human rights law does not clearly spell out a right to protection and relief from disasters, the combined analysis of various provisions of international human rights law suggests that this is implied. ${ }^{20}$ A natural hazard, defined as a dangerous phenomenon, substance, human activity or condition, may lead to a disaster that negatively affects the enjoyment of various human rights, such as the right to life, property and livelihoods. ${ }^{21}$ Destruction linked to disasters may give rise to human displacement and various human rights violations, including sexual violence. ${ }^{22}$

Literature suggests that natural disasters affect most severely the vulnerable sector of the population. ${ }^{23}$ This is so especially because those that are often subject to discrimination and lack opportunities in a given society will experience similar patterns of exclusion in the event of a natural disaster. Furthermore, because of their pre-existent exclusion, it is likely that these individuals already occupy risky areas and live in precarious housing. ${ }^{24}$ Groups that are likely to experience the negative impact of natural hazards more severely are women, children, people with disabilities, the elderly, indigenous communities, and minorities.

As broadly discussed, vulnerability to disasters caused by natural hazards is very much linked to social factors such as the size and structure of the economy, labor markets, urban and rural planning, infrastructure, political voice, and social networks. ${ }^{25}$ Scholars acknowledge that risk linked to the

20 G. Kent, 'The human right to disaster mitigation and relief', 3 Environmental Hazards 137 (2001) at 137 .

21 See the website of the UN International Strategy for Disaster Reduction, http://www .unisdr.org/we/inform/terminology (last accessed 26 November 2014).

22 B. Wisner, 'Risk and the Neoliberal State: Why Post-Mitch Lessons Didn't Reduce El Salvador's Earthquake Losses', 25 Disasters 251 (2001).

23 See, e.g., M. Bizzarri, 'Protection of Vulnerable Groups in Natural and Man-Made Disasters', in A. de Guttry, M. Gestri and G. Venturini (eds.), International Disaster Response Law 381 (2012), at 386-389; N. Zack, Ethics for Disaster (2009), at 108.

24 B. Wisner, 'Marginality and vulnerability: Why the homeless of Tokyo don't "count" in disaster preparations', 18 Applied Geography 25 (1998), at 26; G. Wilches-Chaux, 'The Global Vulnerability' in Y. Aysan and I. Davis (eds.), Disasters and the Small Dwelling: Perspectives for the UN IDNDR 30 (1992).

25 See e.g. J. Barnett, 'Environment Security', in J. P. Burgess (ed.), The Routledge Handbook of New Security Studies (2010). Other ways of identifying vulnerability include the self-assessment by communities of their capabilities and strengths. One example is the 
environment are not equally distributed between and within countries, with those most exposed to risk being the poorest people in the poorest societies. ${ }^{26}$ Thus, they argue that environmental security can be achieved through changes in social systems aiming to reduce people's exposure to risk. Researchers in the field of sociology ${ }^{27}$ also tend to emphasize that disasters are outcomes of processes, and are originated within the social order, not outside it in "the natural system." In other words, disaster events are not discrete events "concentrated in time and space", and natural hazards, such as earthquakes and floods, are considered triggers rather than causes of disasters. ${ }^{28}$

What are the characteristics and circumstances of a community, system, or asset that make it vulnerable to the damaging effects of a hazard? The common factors include legacies of colonialism and imperialism, exploitation of natural resources, dictatorship, massive and increasing poverty, income disparity, migration, rapid and uncontrolled urbanization (settlements often located in areas prone to landslides, floods, and other disasters), inappropriate land use, environmental degradation, and climate change. ${ }^{29}$ The Risk Reduction Index research project, for example, provides an in-depth analysis of risk reduction indicators, grouping them into the following categories: environment and natural resources; socioeconomic conditions; land use and the built environment; and governance. ${ }^{30}$

Participatory Action Research (PAR), which is a dialogical process in which communities are not merely recipients of external knowledge and aid, but which facilitates their own reflection and knowledge sharing. This forms the basis for community-based disaster management and allows communities for example to exchange on their experiences coping with natural disasters.

26 Zack, supra note 23, suggests that "disaster magnifies social inequality", and "the lack of [disaster] preparation by and for the most disadvantaged in itself further disadvantages them", should they face a disaster.

27 We are referring here mainly to the presentation by Kathleen Tierney Dept. of Sociology \& Institute of Behavioral Science, Natural Hazards Center, University of Colorado presented at The University of Copenhagen, 1 November 2013, available at http:// changingdisasters.ku.dk/pdf/kick-off-2013/Kathleen-Tierney_Changing-Disasters.pdf/ (last accessed 26 November 2014). See also C. E. Fritz, 'Disaster', in R. K. Merton and R. A. Nisbet (eds.), Contemporary Social Problems 651 (1961); and C. E. Althaus, 'A Disciplinary Perspective on the Epistemological Status of Risk', 25 Risk Analysis 567 (2005).

28 See, for example, Fisher, supra note 12.

29 See M. Thompson, 'Civil society and disaster', in B. Wisner, J.C. Gaillard and I. Kelman (eds.), Handbook of Hazards and Disaster Risk Reduction 723 (2012), at 730.

30 Risk Reduction Index 2013: Risk Reduction Index in West Africa, http://resources.daraint .org/rri/rri_eng.pdf (last accessed 26 November 2014). 
In addition to these factors, other related factors include communities' lack of disaster-related information, thus making it difficult for them to be involved in the decision-making in all phases of the disaster management cycle, such as disaster prevention, disaster response, disaster rehabilitation/recovery, and deepening their vulnerability. ${ }^{31}$ For example, Wisner suggests that lack of information may particularly affect migrant workers, for they may not fluently speak the local language and tend to avoid interaction with the State bureaucracy. ${ }^{32}$

As suggested earlier, the conceptualization of hazards and vulnerability implies that the occurrence of a flood, for instance, needs not result in disaster. ${ }^{33} \mathrm{~A}$ flood that occurs in a place with neither human population nor economic, social, and environmental assets will not necessarily lead to a disaster, and vulnerability can be avoided or minimized through joint efforts towards disaster risk reduction, i.e., actions taken already before a society is affected by natural hazards. ${ }^{34}$ Particularly important is the adoption of legislation on disaster risk reduction that takes into account human rights. To summarize, the HRBA to DRR legislation emphasizes broad popular participation in political life; consultation with the local communities, in particular the vulnerable sections within such communities, in decision-making processes; access to justice; transparency, and accountability.

Three key principles to bear in mind in this process of empowerment are: 1) participation, 2) information, and 3) non-discrimination. Participation indicates that all parts of society, including impacted communities, grassroots organizations, minorities, rural populations, and women, play an active role and express their priorities; the participation shall be active, free, and meaningful. The population shall be routinely consulted regarding DR R plans to protect the communities, thus ensuring there is a legal framework in place which is designed in a way that is sensitive to the specific needs and attributes of the

31 T. Cannon, 'Vulnerability analysis and the explanation of "natural" disasters', in A. Varley (ed.), Disasters, Development and Environment (1994), at 13; Gaillard, supra note 7; M.J. Watts, and H.G. Bohle, 'The space of vulnerability: the causal structure of hunger and famine', 17 Progress in Human Geography 1 (1993), at 43-67; Wisner et al., supra note 5.

32 Wisner, supra note 24.

33 In other words, UNISDR expresses this concept as a formula: "Risk = Hazard xVulnerability". See United Nations International Strategy for Disaster Reduction, 'Living with Risk: A Global Review of Disaster Reduction Initiatives, Volume II Annexes', 2004, at 6.

34 J. Twigg, 'Disaster Risk Reduction: Mitigation and preparedness in development and emergency programming', Humanitarian Practice Network at Overseas Development Institute, Good Practice Review, Number 9, March 2004. 
community. ${ }^{35}$ Information, especially on environmental hazards, needs to be shared to encourage local populations to take part in joint community efforts; information shall be transparent and easily accessible to the community. Finally, non-discrimination suggests that the government pay particular attention to groups that are likely to be excluded because of their gender, economic status, social condition, color, language, or other factors. This should also be the case in relation to laws covering DRR.

Aiming to explore links between the HRBA and DRR, we considered the preliminary findings arising from a research project jointly conducted by the IFRC and the United Nations Development Programme (UNDP), which focused on the use of legislation as a tool for enhancing DRR. For the purposes of the current paper we focused our analysis on four countries' legislative framework relevant to DRR, looking especially at whether, and to what extent, they include a human rights perspective. The chosen countries are Ethiopia, Nepal, Brazil, and the Dominican Republic.

The IFRC 2013 report published in the joint IFRC-UNDP project distinguished four ways in which States integrated DRR into their national legal frameworks. ${ }^{36}$ The first type was "No Specific Law on Natural Disasters", referring to countries whose legal frameworks were not tailored to address issues pertaining to natural disasters. The second type, a "Response Focus", refers to legislation on natural disasters that is largely limited to specific types of natural hazards, though it may also include policies on broader disaster management and/or DRR issues. The third type of legislation, so-called "Disaster Management (DM) Focus", refers to national laws that include some aspects of prevention, early warning, mitigation, response and/or recovery. Finally, the

35 S. Akbar, 'A Rights-Based Approach to Housing Restitution in Post-Flood Pakistan's Khyber Pakhtunkhwa Province', 21 Transnational Law \& Contemporary Problems 853 (2013); T. Izumi and R. Shaw, 'Role of NGOs in Community-Based Disaster Risk Reduction Community-Based Disaster Risk Reduction Community', 10 Environment and Disaster Risk Management 35 (2012); S. K. Kafle and Z. Murshed, 'Community-based disaster risk management for local authorities: Participant's Workbook', Asian Disaster Preparedness Center (ADPC), Pathumthani, 2006; A. Heijmans, 'The social life of community-based disaster risk reduction: Origins, politics and framing, disaster studies', Working Paper 20, Aon Benfield UCL Hazard Research Center, 2009; M. Oxley, 'Developing a Post-2015 HFA Policy Framework', GNDR Discussion Paper, 2012.

36 According to the IFRC, the legal framework relevant to DRR includes: disaster management laws, building and land management codes, environmental protection rules, and flood and fire management laws. See International Federation of Red Cross and Red Crescent Societies, 'Better Laws, Safer Communities? Emerging Themes on How Legislation Can Support Disaster Risk Reduction', May 2013, at 8. 
fourth category of legislation refers to "Disaster risk management legislation that considers disaster risk reduction is an integral part of the disaster management legal framework from national to local level". ${ }^{37}$ For the purposes of the current paper we selected a country located in each respective category, as identified in the IFRC study.

Ethiopia falls into the first category of having no dedicated statute on natural disasters. Due to its response focus, Nepal falls into the second category. Brazil falls into the third category as its legal framework focuses on disaster management. And finally, the Dominican Republic focuses on DRR and therefore fits into the last category. We found that in Ethiopia, in addition to poor social and economic conditions that make people vulnerable to natural hazards, there are insufficient efforts to ensure there is a legal framework to include communities in the process of reducing disaster risk.

According to the IFRC report there is hardly any engagement with local communities regarding DRR practices and policies, and the involvement of communities in legal processes such as environmental impact assessments and planning is very limited. Knowledge of laws and policies is equally quite reduced or even non-existent. Finally, communities suffer from a severe lack of communication regarding DRR projects and awareness promoting their involvement in legal processes. ${ }^{38}$

In contrast, the Dominican Republic case shows that its Disaster Risk Management Act (DRM Act) ${ }^{39}$ addresses the close link between vulnerability and natural disasters. It recognizes poorer communities among those most vulnerable to disasters, and who need to have their capacity enhanced to reduce disaster risk. The Act can be praised for its rights-based approach to DRR, which is a result of the government's gradual efforts over the last decade in improving the legislative framework and developing new ways to modernize its democratic system. Although the new Dominican Republic Constitution of January 2010 does not address protection against natural or man-made hazards per se, it refers to the right to life, the protection of human dignity, the right to liberty and personal security, and the right to an adequate standard of living, including food security, housing, health, work, and education. ${ }^{40}$ Thus, it intends to show that it is the duty of the State to provide security and protection for its citizens. The DRM Act also makes reference to

\footnotetext{
$37 \quad$ Ibid., at 8.

38 Ibid., at 15 .

39 Law No. 147 of 2002.

40 Constitution of the Dominican Republic, 2010, articles 37, 38, 54, 59, 61, 62, 63 and 67 (i).
} 
the right to life and personal physical integrity, as well the protection of material goods from possible disasters. ${ }^{41}$ These are positive legal developments pointing towards the link between natural disasters and human rights. ${ }^{42}$

As suggested by Fisher, "legal frameworks for risk reduction should also include specific measures to ensure that good intentions are actually carried out." ${ }^{33}$ With this in mind we looked at whether there are effective mechanisms in DRR laws available to all those wishing to make complaints. Accountability implies that the government shall be answerable for acts and omissions, including in the event of disasters. It is an obligation of States to provide victims of human rights violations with effective remedies, according to article 2(3) ICCPR. That being the case, we argue that claiming the right to protection from preventable disaster losses should be considered a right of every citizen. ${ }^{44}$ In this context what are the options for individuals facing the risk of disaster losses to claiming their rights? Can the accountability process be strengthened through post-disaster legal options available to disaster victims? With these questions in mind we considered national laws, especially those covering DRR, in order to ascertain whether they may be used to hold government officials into account.

Ethiopia has a constitutional provision covering the general protection of individuals from natural and man-made disasters, together with the duty of the State to provide assistance to victims. Although institutional responsibilities are relatively well defined, there is no legal provision clearly indicating the accountability and liability of authorities in case of their (in)action linked to natural disasters. ${ }^{45}$ Also the country does not have legislation acknowledging a right of individuals to receive information relating to imminent natural disasters. ${ }^{46}$ Finally, Ethiopia has no legal mechanism for victims to complain about losses following natural disasters.

41 Law No. 147-02, art. 1.

42 The summaries for Nepal and Brazil regarding empowerment process through law on DRR are placed in Table 1.

43 Fisher, supra note 12 , at 576.

44 This seems to be increasingly acknowledged, for example in the ECtHR 2008 Budayeva case, in which loss of life was found directly linked to the State's failure to take preventive measures to address foreseeable hazards. See Judgment, Budayeva and others v. Russia, Application No. 15339/02, ECtHR, 29 September 2008.

45 International Federation of Red Cross and Red Crescent Societies, 'Ethiopia: Country Case Study Report - How Law and Regulation Supports Disaster Risk Reduction', April 2013 , at 26 .

46 Ibid., at 26-27. 
According to Nepal's 2009 National Strategy for Disaster Risk Management (NSDRM), human rights are to be taken into account in DRR efforts. ${ }^{47}$ However, this is a policy document adopted by government, not a legally binding piece of legislation. Nevertheless, the NSDRM advocates for protecting citizens from avoidable disasters through recognizing the right to a dignified life, and also indicating that the State should not create new risks during recovery and rehabilitation. Authorities shall be sensitive to social justice, inclusion, and equality in regard to gender, ethnicity, people with disabilities, people in poverty, and marginalized communities, including Dalits. ${ }^{48}$ Among the guiding principles of the NSDRM is that people have the right to be protected from disasters. ${ }^{49}$ Although the policy refers to the need for authorities to be accountable to disaster-affected communities, there is no clear accountability mechanism in place, including on specific remedies relating to disaster prevention.

Brazil recognizes, among others, a constitutional right to adequate housing. ${ }^{50}$ Recent initiatives on urban planning led to the adoption of the Statute of the City ${ }^{51}$ and the creation of the Ministry of Cities. These developments suggest a current trend towards improving housing in particular. In a broader sense, however, the country does not have in place a legal provision on mandatory disclosure of disaster risks known to government agencies and/or private actors. ${ }^{52}$ There is also no clear law on State responsibility for omission by authorities in relation to disaster preventative measures, and legislation on disaster risk management (DRM) is rather confusing when assigning responsibilities to different bodies. ${ }^{53}$ Brazil has no national legal provision conferring enforceable rights on citizens in relation to official DRR initiatives. ${ }^{54}$ This can frustrate communities, who are unable to compel authorities to take action on disaster prevention.

47 Article 2.2.1, National Strategy on Disaster Risk Management (NSDRM). See International Federation of Red Cross and Red Crescent Societies, 'Analysis of Legislation Related to Disaster Risk Reduction in Nepal', 2011, at 32.

48 Ibid., at 32.

49 Ibid., at $5^{2 .}$

50 International Federation of Red Cross and Red Crescent Societies (IFRC), 'Analysis of Legislation Related to Disaster Risk Reduction in Brazil', 2011, at 5. For a non-official English translation of the 1998 Brazilian Constitution, see http://www.v-brazil.com/ government/laws/constitution.html (last accessed 20 January 2014).

$5^{1} \quad$ Law 10.257, of 10 July 2001, referred to as the 'Statute of the City'.

$5^{2} \quad$ IFRC, supra note $5^{\circ}$, at 38 .

53 Ibid., at 46.

54 Ibid., at 45 . 
Finally, the Constitution of the Dominican Republic contains reference to the right to life, the right to liberty and security, and the right to an adequate standard of living, including food, housing, health, work, and education. ${ }^{55}$ Although there is no reference in the Constitution in relation to protection against disasters, the Disaster Risk Management Act suggests that rights should guide the national DRM policy. Reference is made to the need to protect life, personal physical integrity, material goods, productive means, and the environment from possible disasters. ${ }^{56}$ However, the country has not adopted precise legislation that clearly provides the possibility of enforcing and protecting these rights. There is also no legislation in place on accountability for disaster losses, damage reparation, or rehabilitation and reconstruction. ${ }^{57}$

The overview of the four countries above suggests that the mere existence of national legislation concerning natural disasters, including legislation relating to DRR, may not be sufficient for effectively advancing this area, especially in terms of guaranteeing enforceable rights to affected citizens. We consider that enhancement of the protection of individuals from natural disasters goes hand in hand with a rights-based approach to DRR. Thus we acknowledge the importance of human rights, especially in community engagement, which is needed throughout this empowerment process. If a government does not perceive the local community as an important actor in DRR, this will translate in limited access to information on the subject to the broad population, reducing the overall community involvement and increasing its vulnerability. We argue it is quite important to ensure a general climate of non-discrimination and respect for civil liberties, also through individuals' participation in collective and public affairs.

From the analysis of our case studies we suggest there might be a correlation between progress in adopting a legislative framework on DRR and the general human rights situation of a country. In case of Ethiopia, a lack of empowerment and engagement of individuals in DRR activities may have its roots in its current political system. According to popular regime indicators, like Polity IV or Freedom House, this is an undemocratic country severely curtailing political and civil rights. Issues of concern in the country relate to the enjoyment of the right to freedom of assembly and association, freedom of speech, freedom of religion, combined with allegations of frequent use of political imprisonment and torture, often linked to different stances in relation to religious beliefs and political views.

\footnotetext{
55 International Federation of Red Cross and Red Crescent Societies, 'Analysis of Legislation Related to Disaster Risk Reduction in the Dominican Republic', 2011, at 43.

$56 \quad$ Ibid., at 44.

57 Ibid.
} 
In other words, we acknowledge that countries may adopt various laws and policies with ambitious goals towards natural disasters. However, if the empowerment of local communities and the overall protection of human rights are neglected, the efficiency and effectiveness of efforts to reduce or manage disaster risk may be severely undermined. Moreover, the lack of general legal accountability mechanisms to hold governments to account translates into less available remedies for individuals affected by disasters. The brief overview of our case studies suggests there are almost none or only very few national remedial mechanisms available to victims of natural disasters. It seems among the countries covered that natural disasters are still very much perceived as 'acts of god', for which States have little to do with, especially in terms of prevention and risk reduction. This leads us to enquire about further legal alternatives open to individuals, the reason why in the next section we shift our focus to human rights mechanisms available at the international level.

\section{Strengthening Accountability through International Mechanisms}

Since the four case studies covered in this paper are parties to different human rights treaties, it is important to analyze what available options there are for those seeking justice through international human rights monitoring mechanisms. In the event that government authorities were aware but did not repair defective disaster warning systems, or did not adopt measures to prevent damage to property that was linked to natural hazards, could individuals claim violation of their rights? In this context, are international mechanisms effective in holding governments into account? The current section focuses on these issues.

Our coverage will focus on two key international human rights treaties adopted in 1966, namely the International Covenant on Civil and Political Rights $^{58}$ (ICCPR, which includes, among others, the right to life), and the International Covenant on Economic, Social and Cultural Rights ${ }^{59}$ (ICESCR, which includes, among others, the right to food, housing, and health). Taking into account that in relation to both treaties States can adopt optional protocols allowing individuals to bring a complaint alleging violation of rights before a specialized monitoring body, we also looked at the First Optional

$58 \quad 1966$ International Covenant on Civil and Political Rights, 999 UNTS 171.

59 ICESCR, supra note 14 . 
Protocol to the ICCPR ${ }^{60}$ and the Optional Protocol to the ICESCR. ${ }^{61}$ Whereas all case studies are parties to the ICCPR and the ICESCR, none of them is party to the Optional Protocol to the ICESCR, which was adopted in 2008. In relation to the First Optional Protocol to the ICCPR, all our case studies, except for Ethiopia, are parties to this particular instrument (see Table 1). None of our case studies made reservations to any of the treaties covered in this paper, meaning that they made no formal attempt to reduce or modify their obligations under these treaties.

According to the table below, individuals who feel their civil and political rights were violated have the possibility of bringing a complaint at the international level in relation to violations of the ICCPR against Nepal, Brazil, or the Dominican Republic. Since Ethiopia is not a party to the optional protocol allowing for an individual complaint mechanism, there is no possibility for individuals who allege violation of rights contained in the ICCPR to bring a complaint against this country at the international level. It is also worth noting that a condition of admissibility for individual petitions at the international level is the exhaustion of domestic remedies. This means that as a general rule, applicants have to seek remedy under available national proceedings before bringing a petition to an international monitoring body.

The practice of the UN Human Rights Committee (HRCee), which is the UN treaty body mandated with the monitoring of States' compliance with their obligations under the ICCPR, reveals no relevant information in relation to the countries studied and natural disasters. The HRCee, for example, has not yet clearly articulated that States have an obligation to protect the right to life of persons likely to be affected by natural disasters, but also it has made no suggestion to the contrary either. This is the conclusion obtained after identifying and analyzing the Committee's assessment of the four countries' periodic reports and complaints brought by individuals arguing violation of the ICCPR.

In relation to economic, social, and cultural rights, we looked at the practice of the UN Committee on Economic, Social and Cultural Rights (CESCR), which monitors the ICESCR. Since none of our case studies is party to the optional protocol allowing for individual petitions, we looked specifically at concluding observations adopted by the CESCR after analysis of States' periodic reports on

6o 1966 Optional Protocol to the International Covenant on Civil and Political Rights, 999 UNTS 171.

61 Optional Protocol to the International Covenant on Economic, Social and Cultural Rights, GA Res. 63/435, 10 December 2008. 
their implementation of the treaty. This practice revealed very few instances in which human rights were linked to natural disasters.

For example, in 2010 the CESCR indicated its appreciation of the positive role played by the Dominican Republic in response to the Haitian earthquake, although it did not further elaborate on this. ${ }^{62}$ In relation to the three other countries, the CESCR made no reference to natural disasters when looking at State compliance with human rights obligations. Be that as it may, one can identify some human rights aspects addressed by the CESCR that may be of relevance in the context of natural disasters, including regarding prevention.

The practice of the CESCR reveals some references to the right to housing, land tenure, and information and participation by civil society in the international human rights reporting. An example of that are its concluding observations made in 2010 after analysis of the report of the Dominican Republic, already referred to. In this document the CESCR noted the adoption of a national decree ordering the eviction of houses built on a river bank, but highlighted the need to take into account human rights obligations when governmental authorities implement such measures, especially in relation to housing and forced evictions. ${ }^{63}$ Since dwellings built on riverbanks may lead to greater erosion and flooding, the situation is also relevant in terms of DRR. The planning of human occupation of suitable areas followed-up by regulation and implementation contributes to reducing the vulnerability of a given society in coping with natural hazards. For example, due to the lack of better options many poor communities recurrently experience flooding, for they tend to occupy more affordable but flood-risk areas, despite knowing them to be subject to periodic floods. The result is that such communities remain in a position of vulnerability and recurrently experience the negative impact of natural hazards.

A further reference to natural disasters was made by the CESCR in 2001 in relation to Nepal, asking the State to continue with agrarian reform and further efforts to address land tenure issues. ${ }^{64}$ Since individuals tend to engage more significantly in prevention efforts for the preservation of their own property, the recognition of title over land is a human rights issue that intersects with DRR measures.

62 See CESCR, Concluding Observations Dominican Republic, E/C.12/DOM/CO/3, 26 November 2010, para. 5 .

63 See CESCR, Concluding Observations Dominican Republic, E/C.12/1994/15, 19 December 1994, para. 27 .

64 See CESCR, Concluding Observations Nepal, E/C.12/1/Add. 66, 24 September 2001, para. 48 . 
Furthermore, in different opportunities the CESCR noted with concern the precarious settlements in which a large part of the world population live, especially the urban poor, for example in concluding observations relating to Brazil and Ethiopia. ${ }^{65}$ This is another issue of relevance to natural disasters, for people living in overcrowded areas in precarious dwellings are vulnerable to natural hazards that may develop into disasters.

Finally, the CESCR also addressed in its practice access to information and participation of civil society in the monitoring of human rights obligations of States. These aspects were mentioned in the CESCR concluding observations relating to Brazil in 2003 and 2009, occasions in which the Committee actually praised the country for its efforts in this sense. ${ }^{66}$

Although the human rights monitoring bodies scantly addressed natural disasters in their monitoring of States' obligations, the references above relating to our case studies suggest that some issues addressed by human rights monitoring bodies are of potential relevance to DRR. International human rights monitoring bodies do not pay particular regard to natural disasters. However, to the extent that human rights issues may relate to natural disasters, the topic may increasingly gain space in the practice of these bodies.

The previous sections suggest that natural disasters may negatively affect human rights, and that individuals who feel their rights were violated may wish to seek redress for such violations. From the current section one may get the general impression that international procedures are relatively few and their effectiveness is not undisputed. It seems a general climate of respect for human rights and community participation could enhance disaster risk reduction efforts, and thus reduce the need for victims to seek post-disaster justice. Participation is also linked to the right to take part in the public affairs of the State, based on article 25 ICCPR. The Human Rights Committee interpreted this article broadly, suggesting that individuals should also participate in public policies in matters that affect them. ${ }^{67}$

For advocacy purposes it is also relevant to have statements of principle and findings by international human rights bodies on the relationship between

65 See CESCR, Concluding Observations Brazil, E/C.12/BRA/CO/2, 12 June 2009, para. 25. See also CESCR, Concluding Observations Ethiopia, E/C.12/ETH/CO/1-3, 31 May 2012, para. 20.

66 See CESCR, Concluding Observations Brazil, E/C.12/1/Add.87, 26 June 2003, para. 14. A similar point was made a few years later; see CESCR, Concluding Observations Brazil, E/C.12/BRA/CO/2, 12 June 2009, para. 4.

67 See Human Rights Committee, General Comment No. 25 (The Right to Participate in Public Affairs) (1996), 'Compilation of General Comments and General Recommendations Adopted by Human Rights Treaty Bodies', HRI/GEN/1/Rev.7 (24 May 2004), para. 5. 
natural disasters and human rights, for this may influence States' policies and laws on the subject. Due to the limited extent of this article our analysis was limited to the two international human rights treaty bodies relevant to the selected treaties reviewed. Further research is needed in order to provide a more comprehensive overview of other possible international human rights monitoring mechanisms of relevance here. This should take into account mechanisms such as the UN Special Rapporteurs (among others the UN Rapporteurs on the Right to Adequate Housing; and on Human Rights and the Environment) and further practice of the Human Rights Council, particularly the Universal Periodic Review. From this brief overview one can suggest that there are potential linkages between human rights and disaster risk reduction, and that the use of the international human rights machinery may well enhance advocacy efforts for States to adopt and implement effective DRR measures.

\section{Conclusion}

The paper provides an account of the importance of linking human rights to natural disasters. It suggests that especially through the adoption of a human rights-based approach and the legal protection of human rights, advances can be made also in the area of disaster risk reduction. The case studies suggest that since the adoption of the Hyogo Framework of Action in 2005 countries have progressed in adopting policies or laws addressing especially disaster risk reduction, though much more needs to be done. One of the issues that should be taken into account during the review process and adoption of a post-HFA mechanism is the potential that human rights may provide for further advancing DRR, for example as advocacy tools or ways of disaster victims to obtaining compensation for disaster losses.

The potential of using human rights for advocacy and possible mechanisms for enhancing accountability is being increasingly acknowledged, for example in a recent study by two leading humanitarian actors in this sector. ${ }^{68}$ In relation to accountability at the national level, our case studies suggest that more attention is being paid to the recognition of the need to protect individuals from natural disasters, but that to date there is only a limited set of tools for individuals seeking to hold governmental authorities to account.

68 See International Federation of Red Cross and Red Crescent Societies (IFRC) and United Nations Development Programme (UNDP), 'Effective Law and Regulation for Disaster Risk Reduction: A Multi-Country Report', 2014, at 72-74 and 89. 
The overview of human rights mechanisms available at the international level suggests that, increasingly, UN treaty bodies are paying attention to natural disasters. However the issue is scrutinized in a rather non-systematic fashion and is being taken only indirectly into account by the key human rights monitoring bodies addressed in the current study. It is suggested that further investigation on the potential use of available international human rights mechanisms is worth being undertaken. This should include other human rights treaties, UN Special Rapporteurs, and the Universal Periodic Review of the Human Rights Council.

The topic is a timely one for more attention is being paid to the link between natural disasters and human rights. For example, the UN International Law Commission in its draft articles on the "protection of persons in the event of disasters" adopted in 2014 made a clear reference to this link. According to article 6 of the draft articles: "Persons affected by disasters are entitled to respect for their human rights." This is an important statement of principle, though there is a clear need for research to develop a more thorough understanding of the subject. The articles shall be further considered by the uN General Assembly, which may lead to the adoption of an international treaty on the subject, clarifying key legal aspects relating to disasters. Therefore it can be concluded that the investigation of how human rights affect and are affected by disasters is at a very early stage, especially in what regards the use of human rights legal framework for advancing DRR efforts. It seems that if both agendas can be merged or at least inform each other, time and resources might be more effectively used, generating a more positive impact on the ground among communities. 


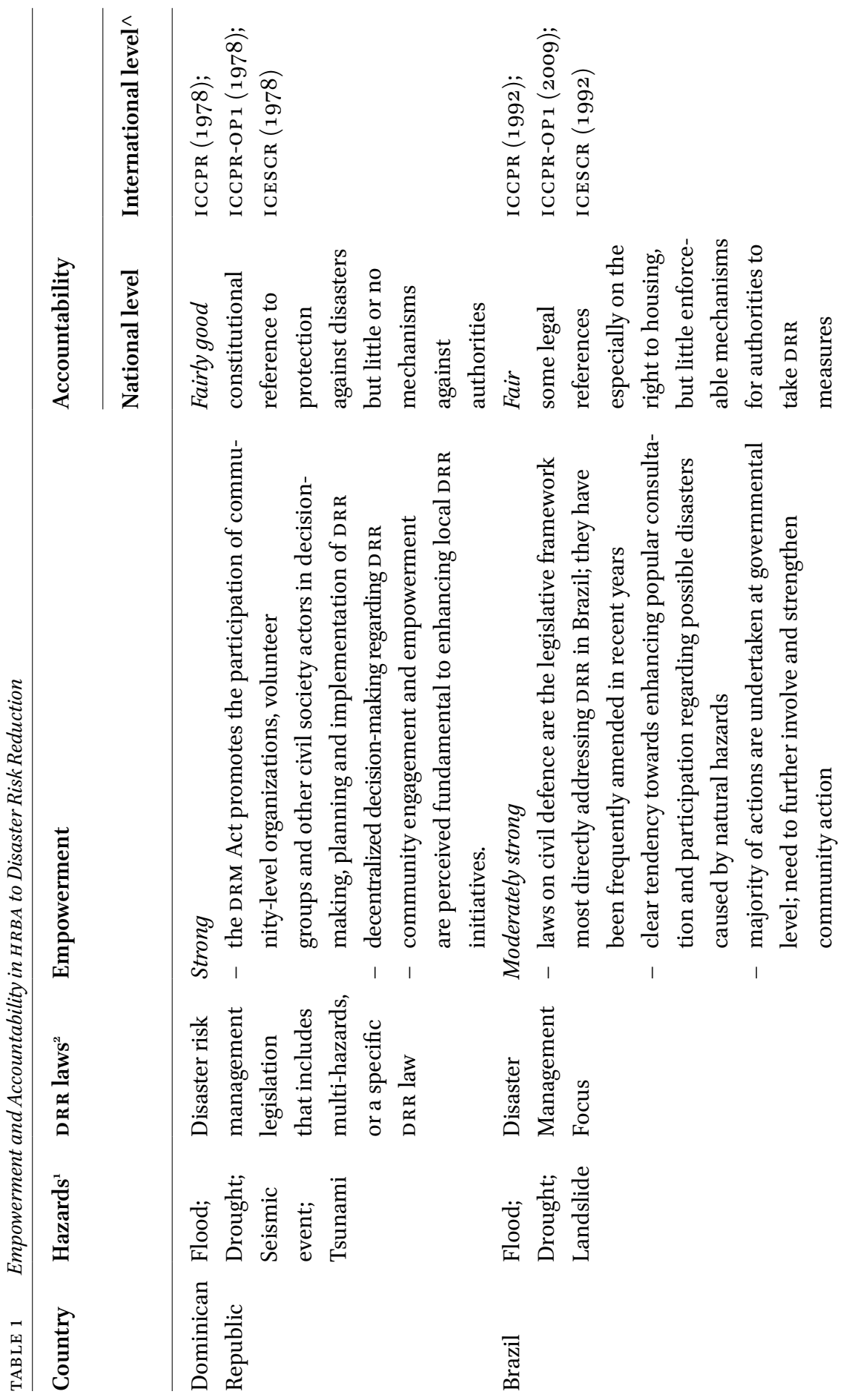




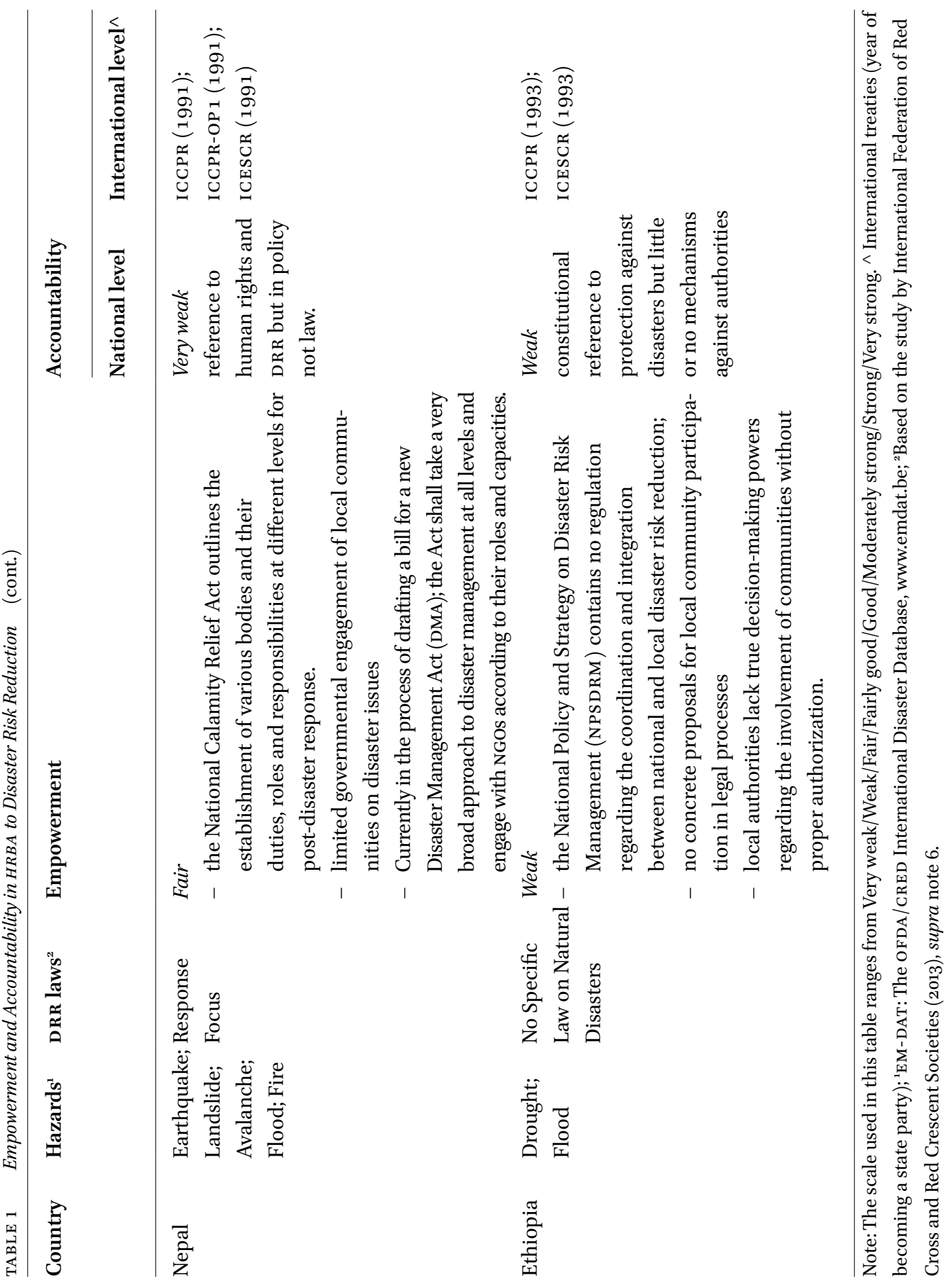

